\title{
Een sensitieve snelle benoemtest voor woordvindproblemen bij patiënten met een laaggradig glioom
}

\author{
Priscilla Ras ${ }^{1}$, Djaina Satoer ${ }^{1}$, Geert-Jan Rutten ${ }^{2}$, \\ Arnaud Vincent $^{1}$, Evy Visch-Brink ${ }^{3}$ \\ ${ }^{1}$ Afdeling Neurochirurgie, Erasmus MC - Universitair Medisch Centrum, Rotterdam \\ ${ }^{2}$ Afdeling Neurochirurgie, Elisabeth-Tweesteden Ziekenhuis, Tilburg \\ ${ }^{3}$ Afdeling Neurologie, Erasmus MC - Universitair Medisch Centrum, Rotterdam
}

\begin{abstract}
Samenvatting
Patiënten met een laaggradig glioom (langzaam groeiende hersentumor) rapporteren vaak woordvindproblemen, terwijl deze met de huidig gebruikte benoemtests in de praktijk vaak niet geobjectiveerd worden. In deze studie worden de resultaten van een sensitieve snelle benoemtest (SBT) voor objecten besproken, toegepast bij deze patiëntengroep.

Via deze nieuwe test werden reactietijden verzameld van 18 patiënten met een vermeend laaggradig glioom en van 20 gezonde participanten. Om uit te sluiten dat bij glioompatiënten tragere reactietijden worden gevonden als gevolg van algehele cognitieve traagheid, zijn de resultaten van een test voor cognitieve snelheid (Trail Making Test-A, TMT-A) meegenomen in het onderzoek. De resultaten op de SBT zijn vergeleken met de resultaten op de klinisch veel gehanteerde Boston Naming Test (BNT) om zo de toegevoegde waarde van de SBT te kunnen evalueren. Tevens is het effect van woordfrequentie en Age of Acquisition (AoA) op de benoemtijden onderzocht.

Glioompatiënten waren significant langzamer in het benoemen van de objecten dan de gezonde participanten. De tragere reactietijden werden niet verklaard door een algeheel tragere verwerkingssnelheid. Ook de BNT-scores konden de lagere reactietijden op de SBT niet verklaren. Een kwalitatieve vergelijking tussen de resultaten van de BNT en de SBT duidde op een hogere sensitiviteit van de SBT voor woordvindproblemen. In de groep gezonde participanten wordt een effect gevonden van woordfrequentie en AoA op de benoemsnelheden, in de patiëntengroep is echter geen effect van deze variabelen waar te nemen.

De resultaten laten een duidelijk verschil in benoemsnelheid zien tussen laaggradige glioompatiënten en gezonde participanten, terwijl patiënten zelden een afwijkende score behaalden op de BNT. Het lijkt zinvol om de SBT te gebruiken in de klinische praktijk,
\end{abstract}

Correspondentieadres:

Dr. D.D. Satoer

Erasmus MC, afdeling Neurochirurgie

Dr. Molewaterplein 40

3015 GD Rotterdam

E-mail: d.satoer@erasmusmc .nl
Dit artikel is gelicentieerd onder de Creative Commons CC BY-NC-ND 4.0 (NaamsvermeldingNietCommercieel-GeenAfgeleideWerken) Internationale Licentie. Gebruik en distributie voor commerciële doeleinden en elke distributie van aangepast materiaal vereist schriftelijke toestemming. 
waarbij reactietijden als een belangrijk component meegenomen worden voor het diagnosticeren van woordvindproblemen bij glioompatiënten.

\section{Summary}

Low grade glioma patients report word finding difficulties during the anamnesis. However, these are often not objectified with naming tests used in clinical practice. The aim of the current study was to develop a sensitive speeded naming test for word finding difficulties in low grade glioma patients.

Reaction times on a picture naming test were obtained for 18 glioma patients and 20 healthy participants. Results of a measure of cognitive speed (Trail Making Test A) were taken into account to exclude the possibility of slower response rates in glioma patients due to overall cognitive slowing. Naming test results were compared with results of a naming test commonly used in clinical practice, the Boston Naming Test (BNT), in order to evaluate the additional value of the speeded naming test. Also, the effect of word frequency and age of acquisition (AoA) on naming latencies was investigated.

Glioma patients were significantly slower than the healthy participants in object naming. The slower naming latencies were not explained by an overall lower speed of processing. BNT scores could not explain the slower naming latencies. A qualitative comparison between results of the speeded naming test and BNT pointed to a higher sensitivity of the naming test for word finding difficulties. Although an effect of word frequency and AoA emerged in the healthy participant group, there was no effect on the naming latencies in the patient group for these variables.

The results showed a clear difference between naming latencies of low grade glioma patients and healthy controls, while patients rarely achieved clinical scores on the BNT. There is support for the use of a speeded naming test in daily clinical practice in which reaction times are included as a critical component for diagnosing word finding difficulties in glioma patients.

\section{Inleiding}

Patiënten met een laaggradig glioom (LGG) hebben vaak stoornissen in de hogere cognitieve functies, zoals aandacht, geheugen, executieve functies en taal, vanwege tumorgroei in functionele gebieden van de hersenen (Taphoorn \& Klein, 2004). Een veelvoorkomende klacht van deze patiënten is dat zij problemen ondervinden met de woordvinding. Onderzoek laat zien dat woordvindproblemen, oftewel anomie, op kunnen treden zowel voor als na chirurgische verwijdering van een tumor (Duffau e.a., 2008; Ilmberger e.a., 2008; Mandonnet e.a., 2007). Verschillende cognitieve functies en beperkingen, waaronder ook woordvindproblemen, kunnen na tumorresectie verslechteren en vervolgens stabiel blijven of verbeteren (Satoer e.a., 2016). De mate waarin eventueel post-operatief herstel van cognitieve functies plaatsvindt verschilt per patiënt (Satoer e.a., 2017).

De door de patiënt gerapporteerde woordvindproblemen worden in de praktijk vaak niet geobjectiveerd met behulp van traditionele diagnostische taaltesten of beoordelingsschalen, omdat deze maten mogelijk niet gevoelig genoeg zijn. Zo konden in het onderzoek van 
Satoer e.a. (2012) anamnestisch gerapporteerde woordvindproblemen van LGG-patiënten niet geobjectiveerd worden met behulp van de Aphasia Severity Rating Scale (Goodglass \& Kaplan, 1983). Het effect van niet-linguïstische cognitieve functies op het benoemen van patiënten met een milde anomie na een beroerte werd onderzocht door Hunting-Pompon, Kendall, \& Bacon Moore (2011). Ook deze patiënten behaalden normale resultaten op taaltests maar bleken beperkt te zijn in hun automatische verwerking en selectieve aandacht, wat ten grondslag zou kunnen liggen aan hun anomie.

De meeste studies waarin het benoemen van LGG-patiënten onderzocht wordt, rapporteren geen reactietijden. Moritz-Gasser e.a. (2012) toonden echter aan dat benoemsnelheid bij LGG-patiënten significant gecorreleerd is aan terugkeer naar professionele activiteiten, één van de belangrijkste factoren in kwaliteit van leven. Ook Bates e.a. (2003) vonden juist in reactietijden, in vergelijking met andere variabelen in benoemgedrag, de grootste correlaties in verschillende talen. Dit suggereert dat het benoemen van afbeeldingen met een tijdslimiet sensitief is voor universele processen die niet gedetecteerd worden door benoemtesten waarin reactietijden buiten beschouwing worden gelaten (Severens e.a., 2005).

In eerder onderzoek waarin LGG-patiënten en gezonde participanten afbeeldingen, geselecteerd uit onderzoek van Severens e.a. (2005) binnen 2000 ms moesten benoemen werd geen verschil gevonden tussen de prestaties van de twee groepen. De tijd die gegeven werd voor het benoemen van de afbeeldingen was wellicht te lang om te kunnen differentiëren tussen patiënten met en zonder milde woordvindproblemen (Stoop, 2009). Dit wordt bevestigd door ander onderzoek waarin de gemiddelde reactietijd van afasiepatiënten en gezonde participanten bij het benoemen van afbeeldingen is gemeten. Vandenberghe e.a. (2005) vonden een gemiddelde reactietijd van $1981 \mathrm{~ms}$ bij patiënten met een primaire progressieve afasie, in vergelijking tot $1363 \mathrm{~ms}$ in de groep gezonde participanten. Wingfield, Brownell, \& Hoyte (2006) rapporteerden een gemiddelde reactietijd van $1967 \mathrm{~ms}$ bij patiënten met een milde afasie. De reactietijden van de gezonde participanten lagen tussen 800 en 1000 ms. Een studie van De Wilde \& Zijlstra (2006) liet een gemiddelde reactietijd zien van $1319 \mathrm{~ms}$ voor glioompatiënten en $927 \mathrm{~ms}$ voor gezonde participanten. Op basis van deze onderzoeksresultaten kan verwacht worden dat de gemiddelde reactietijd voor het benoemen van afbeeldingen voor afasiepatiënten tussen de 1000 en 2000 ms ligt, terwijl gezonde participanten reactietijden rond $1000 \mathrm{~ms}$ behalen.

De tijd die een patiënt nodig heeft om het goede woord bij een afbeelding te activeren kan een indicatie zijn van lichte woordvindproblemen. Hoewel benoemtaken zoals de Boston Naming Test (BNT; Kaplan e.a., 1983) en de Graded Naming Test (McKenna \& Warrington, 1983) bruikbaar zijn gebleken in het diagnosticeren van woordvindproblemen, hebben zij één nadeel: geen van deze tests houdt rekening met de reactietijd van de patiënt. De BNT heeft wel een officiële tijdslimiet van 20 seconden per item volgens Nederlands normeringsonderzoek (Roomer e.a., 2011), maar deze tijdsrestrictie wordt in de klinische praktijk zelden gehanteerd bij hersentumorpatiënten en zou te lang zijn volgens de door ons verwachte grens van 1000-2000 ms. Hierdoor worden lichte woordvindproblemen wellicht ten onrechte niet gedetecteerd.

Van een aantal factoren is aangetoond dat zij invloed uitoefenen op de snelheid waarmee afbeeldingen benoemd worden, zoals lexicale factoren (name agreement, Age of Acquisi- 
tion (AoA) en woordfrequentie), fonologische factoren (woordlengte in aantal lettergrepen of fonemen), visuele factoren (visuele complexiteit) en semantische factoren (concept $f a$ miliarity en imageability) (Alario e.a., 2004). Ook demografische variabelen zoals leeftijd, geslacht en opleiding zouden van invloed zijn op de benoemsnelheid (Randolph e.a., 1999).

Patiënten met een LGG rapporteren vaak problemen op het gebied van taal (Satoer e.a., 2013) en specifiek klagen zij over milde woordvindproblemen die met de huidige benoemtesten niet altijd geobjectiveerd worden. Het doel van de huidige studie is om deze gerapporteerde milde woordvindproblemen te diagnosticeren met een S(ensitieve) S(nelle) $\mathrm{B}$ (enoemtest) (SBT) die in de klinische praktijk gebruikt kan worden. Hiertoe is onderzocht of LGG-patiënten langzamer zijn dan gezonde participanten in het benoemen van afbeeldingen. Eveneens is nagegaan of demografische gegevens alsmede woordfrequentie en de taalverwervingsleeftijd de reactietijden beïnvloeden. De resultaten van de SBT worden vergeleken met de resultaten op een traditionele benoemtest, de BNT. Tenslotte wordt nagegaan in hoeverre een algemene traagheid in reageren, gemeten met de Trail Making Test- $A$ (TMT-A), onderdeel van de Delis-Kaplan Executive Function System (D-KEFS) testbatterij, verantwoordelijk zou kunnen zijn voor de prestaties op de SBT.

\section{Methoden}

\section{Proefpersonen}

De onderzochte patiëntengroep bestaat uit patiënten die onder behandeling waren in het Erasmus Medisch Centrum Rotterdam of Elisabeth-Tweesteden Ziekenhuis Tilburg voor een LGG. Deze patiënten werden allen neuropsychologisch onderzocht in het Erasmus Medisch Centrum. Het neuropsychologisch onderzoek (NPO) vond plaats kort vóór en 3 of 12 maanden na de hersenoperatie. De data die in deze studie gebruikt zijn, werden verkregen tijdens deze NPO's. De groep gezonde participanten bestaat uit deelnemers die geselecteerd zijn uit verschillende populaties (Universiteit Leiden, en een aantal welwillende anderen) en is zo goed mogelijk gematched met de patiëntengroep.

Inclusiecriteria voor de patiëntengroep waren: 20-60 jaar oud, Nederlands als moedertaal, een operabel (preoperatief) of onlangs verwijderd (maximaal één jaar post-operatief) LGG, geen ernstige visuele problemen (bril of lenzen werden geaccepteerd, zolang de patiënt hiermee een intact zicht had) en geen andere neurologische of psychiatrische stoornissen die zouden kunnen leiden tot een beperkte cognitie. Inclusiecriteria voor de gezonde groep participanten waren: 20-60 jaar oud, Nederlands als moedertaal, geen neurologische of andere spraak- en taalstoornissen, geen visuele (bril of lenzen werd weer geaccepteerd zolang de proefpersoon hiermee intact zicht had) of psychiatrische stoornissen. Van alle deelnemers werden demografische gegevens verzameld: leeftijd, geslacht en hoogst genoten opleidingsniveau. Het opleidingsniveau werd vervolgens geclassificeerd volgens de schaal van Verhage (1964). 


\section{Testmateriaal}

Er zijn 55 zwart-wit lijntekeningen geselecteerd afkomstig uit eerder onderzoek van De Wilde \& Zijlstra (2006) en Snodgrass \& Vanderwart (1980). Deze werden met behulp van E-Prime 2.0 software (Psychology Software Tools, Pittsburgh, PA) digitaal gepresenteerd op een laptopscherm. De stimuli waren verdeeld over negen semantische categorieën volgens het international picture naming project (Bates e.a., 2003): voedsel (4 afbeeldingen), mensen (1 afbeelding), voertuigen (5 afbeeldingen), lichaamsdelen ( 2 afbeeldingen), kleine en grote voorwerpen (19 afbeeldingen), dieren (15 afbeeldingen), kledingaccessoires (4 afbeeldingen) en natuurverschijnselen (5 afbeeldingen).

Bij het selecteren van de afbeeldingen voor het huidige onderzoek is rekening gehouden met de $H$-statistiek voor de benoemovereenkomst. Alle geselecteerde afbeeldingen werden in een onderzoek van Severens e.a. (2005) met hetzelfde woord benoemd door alle proefpersonen. De $H$-statistiek voor de afbeeldingen varieerde van 0 tot 0.31 . Voor de aanvullende analyse met betrekking tot de factoren 'woordfrequentie' en 'AoA' die reactietijden bij het benoemen van afbeeldingen zouden kunnen beïnvloeden, is gebruik gemaakt van woordfrequenties verkregen uit de CELEX lexicale database (Kerkman e.a., 1995). AoA-waarden zijn verzameld vanuit de normen voor vier- en vijfletter woorden van Ghyselinck, Custers, \& Brysbaert (2003) en van Ghyselinck e.a. (2003).

Om een effect van volgorde in de afbeeldingen op de reactietijden (Szekely e.a., 2003) uit te sluiten, zijn twee lijsten met een verschillende volgorde van de afbeeldingen gebruikt. Voor de registratie van reactietijden is een voice-key en een microfoon gebruikt. Om de mogelijkheid uit te sluiten dat er langere reactietijden gevonden worden in de patiëntengroep door algemene cognitieve traagheid, door de hersenschade of gebruikte medicatie (zoals anti-epileptica), zijn resultaten op de TMT-A, als maat voor cognitieve snelheid meegenomen in het onderzoek. Om een evaluatie te kunnen maken van de toegevoegde waarde en klinische toepasbaarheid van de snelle benoemtest bij het diagnosticeren van woordvindproblemen in vergelijking tot huidige gebruikte benoemtests, werden resultaten behaald op de BNT eveneens in het onderzoek betrokken.

\section{Procedure}

$\mathrm{Na}$ het verkrijgen van informed consent werden de gezonde participanten individueel getest met de SBT. De SBT bij de patiënten werd afgenomen als onderdeel van het NPO in het Erasmus MC. Iedere deelnemer ontving standaardinstructies waarin het onderzoek werd uitgelegd en waarbij gevraagd werd iedere afbeelding zo snel en goed mogelijk in één woord te benoemen, zonder hierbij andere geluiden te maken (bijv. mondsmakken, hoesten). Om de deelnemers te laten wennen aan de voice-key en de proefleider de gelegenheid te geven de apparatuur af te stellen, werden eerst in een oefensessie getallen en geometrische vormen benoemd.

De stimuli werden gepresenteerd via E-Prime 2.0. De procedure was als volgt: in het midden van het scherm werd gedurende $2000 \mathrm{~ms}$ een zwart kruis tegen een witte achtergrond afgebeeld. Hierna werd de zwart-wit afbeelding in het midden van het scherm getoond. Zo- 
dra een respons geregistreerd werd door de voice-key, verdween de afbeelding, en werd het scherm wit. De proefleider beoordeelde dan de respons van de deelnemer door één van de knoppen op de serial response box in te drukken: 1 voor een correcte respons, 2 voor een incorrecte respons of een incorrecte registratie door de voice-key. Alleen de correcte responsen zijn gebruikt voor de verdere analyses. Zodra de 1- of 2-respons door de proefleider gegeven werd, kwam het zwarte kruis weer in beeld.

Om de deelnemers bekend te maken met het type afbeeldingen en de manier van presenteren, werden eerst drie oefenafbeeldingen getoond. Hierna startte het echte onderzoek en werden alle 55 afbeeldingen, met twee extra afbeeldingen hieraan voorafgaand getoond. De twee extra afbeeldingen hadden als doel te controleren voor mogelijke starteffecten op de benoemsnelheden en zijn niet gebruikt in de verdere analyses.

\section{Statistische analyse}

Met behulp van een tweezijdige T-test werden de demografische gegevens (leeftijd en opleidingsniveau) van de twee groepen vergeleken. Vervolgens is een eenzijdige T-test gebruikt om te onderzoeken of de benoemsnelheden van de patiënten langer waren dan die van de gezonde participanten. Tevens is een eenzijdige T-test gebruikt om te onderzoeken of de goedscores voor patiënten lager waren dan die van gezonde participanten. Met een multipele regressieanalyse (MRA) is de invloed van de TMT-A en BNT z-scores op de gestandaardiseerde gemiddelde benoemsnelheid onderzocht. Om de invloed van de factoren woordfrequentie en AoA op de benoemsnelheden te kunnen onderzoeken, is ook een MRA gebruikt.

Voor beide tests is het aantal gemaakte fouten (foutief benoemd of geen reactie) geanalyseerd. Aanvullend zijn er kwalitatieve vergelijkingen gemaakt van de fouten op de BNT en de SBT. Voor de BNT-scores zijn de normen van de originele test gebruikt, waarbij rekening gehouden wordt met leeftijd. Er zijn z-scores berekend voor de BNT en de SBT op basis van resp. gepubliceerde normen en de gegevens van de groep gezonde participanten. Om de zscores van de twee tests te vergelijken, zijn de z-scores van de SBT vermenigvuldigd met -1, zodat voor beide tests een negatieve z-score duidt op een lagere prestatie op de test in vergelijking tot een positieve score. Scores werden als afwijkend beoordeeld wanneer deze meer dan twee standaardafwijkingen onder het gemiddelde van de groep gezonde participanten lagen.

Voor iedere afbeelding van de SBT is de gemiddelde reactietijd en de standaardafwijking van de groep gezonde participanten berekend, gebruik makend van de beschrijvende statistieken. Een afkappunt van twee standaardafwijkingen boven de gemiddelde reactietijd per item in de groep gezonde participanten is gebruikt om onderscheid te maken tussen de aan- of afwezigheid van woordvindproblemen. 
Tabel 1: Demografische variabelen gezonde participanten en glioompatiënten en tumorgerelateerde variabelen van 18 glioompatiënten

\begin{tabular}{|c|c|c|c|c|c|c|}
\hline Variabele & Groep & Gemiddelde & Std afwijking & $\mathbf{t}$ & df & $\begin{array}{l}\text { Sig. } \\
\text { zijdig) }\end{array}$ \\
\hline \multirow[t]{2}{*}{ Leeftijd } & Patiënten & 40.06 & 10.87 & & & \\
\hline & Gezonde participanten & 40.10 & 11.48 & 0.01 & 36 & .99 \\
\hline \multirow[t]{2}{*}{ Opleiding } & Patiënten & 5.39 & 0.98 & & & \\
\hline & Gezonde participanten & 5.75 & 0.79 & 1.26 & 36 & .22 \\
\hline Variabele & Groep & Groep & $\begin{array}{l}\text { Aantal per- } \\
\text { sonen }\end{array}$ & Perce & age & \\
\hline \multirow[t]{4}{*}{ Geslacht } & Patiënten & Man & 9 & 50 & & \\
\hline & & Vrouw & 9 & 50 & & \\
\hline & Gezonde participanten & Man & 9 & 50 & & \\
\hline & & Vrouw & 10 & 50 & & \\
\hline \multirow[t]{3}{*}{ Handigheid } & Patiënten & Links & 2 & 11.11 & & \\
\hline & & Rechts & 16 & 88.89 & & \\
\hline & & Ambidexter & 0 & 0 & & \\
\hline \multirow{2}{*}{$\begin{array}{l}\text { Tumorlokalisatie } \\
\text { (hemisfeer)* }\end{array}$} & Patiënten & Links & 12 & 66.67 & & \\
\hline & & Rechts & 4 & 22.22 & & \\
\hline \multirow{2}{*}{$\begin{array}{l}\text { Tumorgraad (vol- } \\
\text { gens WHO classifi- } \\
\text { catie)** }\end{array}$} & Patiënten & Laaggradig & 13 & 72.22 & & \\
\hline & & Hooggradig & 2 & 11.11 & & \\
\hline \multirow{2}{*}{ Recidiviteit ${ }^{* * *}$} & Patiënten & Niet & 15 & 83.33 & & \\
\hline & & Wel & 2 & 5.56 & & \\
\hline
\end{tabular}

* Van twee patiënten mist data betreffende de tumorlokalisatie

** Van drie patiënten mist data betreffende de tumorgraad

*** Van twee patiënten mist data betreffende recidiviteit

\section{Resultaten}

De patiëntengroep bestond uit 18 patiënten (3 pre-operatief, 15 post-operatief) die zijn gediagnosticeerd met een vermeend LGG (9 mannen en 9 vrouwen). De groep gezonde participanten bestond uit 20 deelnemers (10 mannen en 10 vrouwen). De beide groepen verschilden niet in leeftijd [ $t(36)=-.012, p=.99]$ en opleidingsniveau volgens de classificatie van Verhage (1964) $[t(36)=-1.26, p=.22]$ (zie Tabel 1).

Twee van de 55 afbeeldingen die gebruikt zijn in de SBT werden door meer dan $50 \%$ van de proefpersonen niet juist benoemd in zowel de patiëntgroep als in de gezonde participantengroep. Dit waren afbeeldingen van 'een pauw' en 'een schommel'. Hoewel alle afbeeldingen gekozen zijn op basis van hun benoemovereenkomst $(H=0.14$ voor beide afbeeldingen), werden meerdere alternatieve namen aan deze afbeeldingen gegeven. In veel gevallen werden de afbeeldingen geheel niet benoemd. Vanwege de grote hoeveelheid mis- 
sende waarden voor deze afbeeldingen, zijn deze uitgesloten van verdere analyses. De volgende analyses zijn daarom uitgevoerd op de data van de correcte responsen van de overige 53 afbeeldingen, waarbij er in de groep gezonde participanten nog $8.06 \%$ missende waarden waren van de totale hoeveelheid responsen en in de patiëntengroep $11.43 \%$.

\section{Vergelijking van benoemsnelheden tussen de twee groepen}

De LGG-patiënten waren significant langzamer in het benoemen van de afbeeldingen dan de gezonde participanten (LGG: $M=797.09, S D=167.80$; gezond: $M=645.20, S D=47.66$; $t(36)=3.88, p=.00$ ) (zie Figuur 1). Het gemiddelde verschil tussen de groepen was 151.89 ms met een $95 \%$ betrouwbaarheidsinterval van 72.56 - 231.22 ms. De effectgrootte was aanzienlijk $(d=1.41)$.

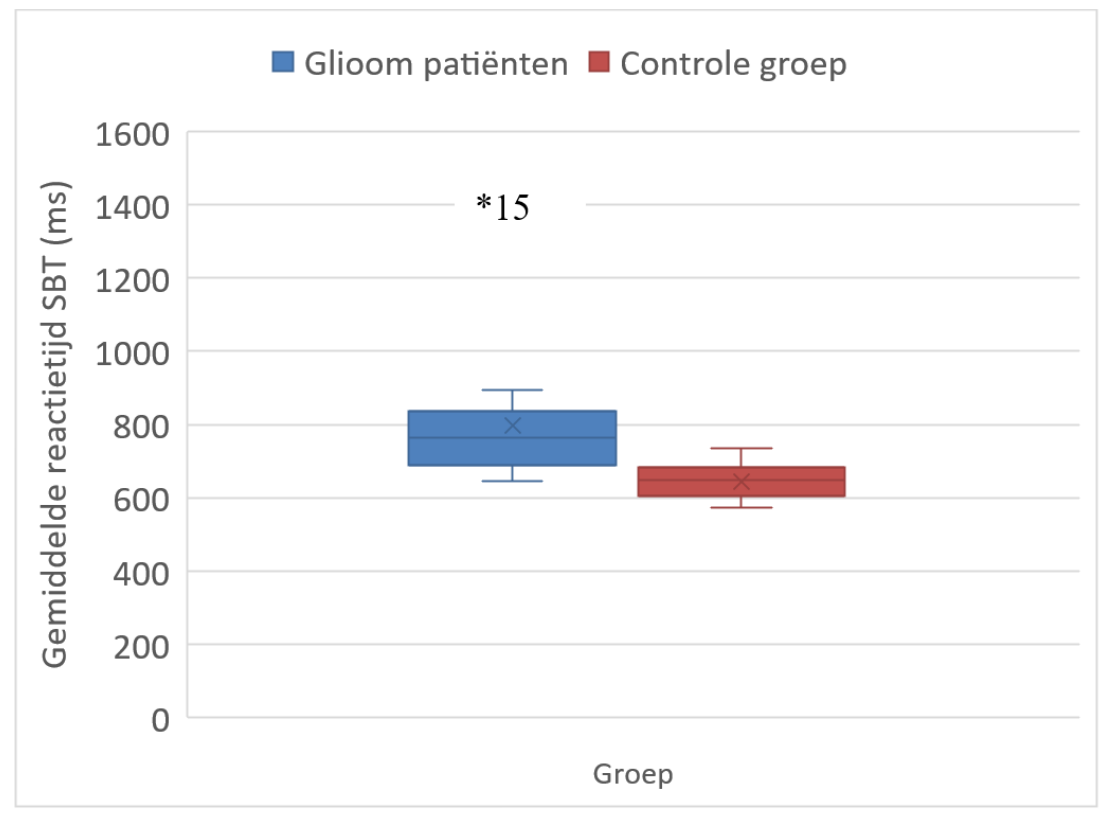

Figuur 1: Gemiddelde Reactietijden (ms) van Glioompatiënten en Gezonde Participanten op de SBT. ${ }^{*} 15$ is een uitschieter met een erg hoge gemiddelde reactietijd op de SBT.

\section{Onderzoek naar de proportie verklaarde variantie door TMT-A en BNT scores}

Met behulp van de multipele regressieanalyse werd een insignificant model gevonden $F$ (2, 15 ) $=.465, p=.637$. Het model verklaarde $6.7 \%$ van de variantie (Adjusted $R^{2}=-.067$ ), duidend op een erg lage samenhang of afwezigheid van samenhang. Tabel 2 geeft meer informatie over de predictor variabelen in het model. TMT-A z-scores en BNT z-scores waren beiden niet voorspellend voor de benoemsnelheden van veronderstelde LGG-patiënten. De twee onafhankelijke variabelen waren niet significant gecorreleerd, de tolerantie was 0.96, er was geen probleem voor de validiteit van de multipele regressieanalyse. De patiëntengroep had een gemiddelde z-score op de TMT-A ten opzichte van de normgroep $(z=0.039$ ). 
Tabel 2: Gestandaardiseerde Regressiecoëfficiënten voor de Variabelen in het Model

\begin{tabular}{llll}
\hline Variabele & B & SE B & $\beta$ \\
\hline Gestandaardiseerde TMT-A-score & 15.46 & 29.11 & 0.14 \\
Gestandaardiseerde BNT-score & -20.58 & 22.95 & -0.23 \\
\hline
\end{tabular}

\section{Kwalitatieve vergelijking van patiënten met een afwijkende score op de BNT en SBT}

Figuur 2 toont de z-scores van de BNT en SBT voor alle patiënten. Zes patiënten behalen een afwijkende score op de BNT $(3,6,7,11,12,15)$. Tien patiënten hebben een afwijkende score op de SBT $(3,5,6,7,9,10,11,13,14,15)$. Eén patiënt (12) met een afwijkende score op de BNT wordt op de SBT niet als afwijkend geclassificeerd. Vijf patiënten $(5,9,10,13,14)$ die op de SBT een afwijkende score behalen, scoren op de BNT niet afwijkend. Geen van de 3 pre-operatief geteste patiënten behaalden een afwijkende score op de SBT $(1,4,12)$, twee van hen tevens niet op de BNT $(1,4)$. Over het algemeen, hoewel niet significant, behalen patiënten lagere z-scores op de SBT dan op de BNT (SBT $M=-3.19, S D=3.52$, BNT $M=$ -1.70, $S D=1.87)[t(36)=-1.74, p=.10]$.

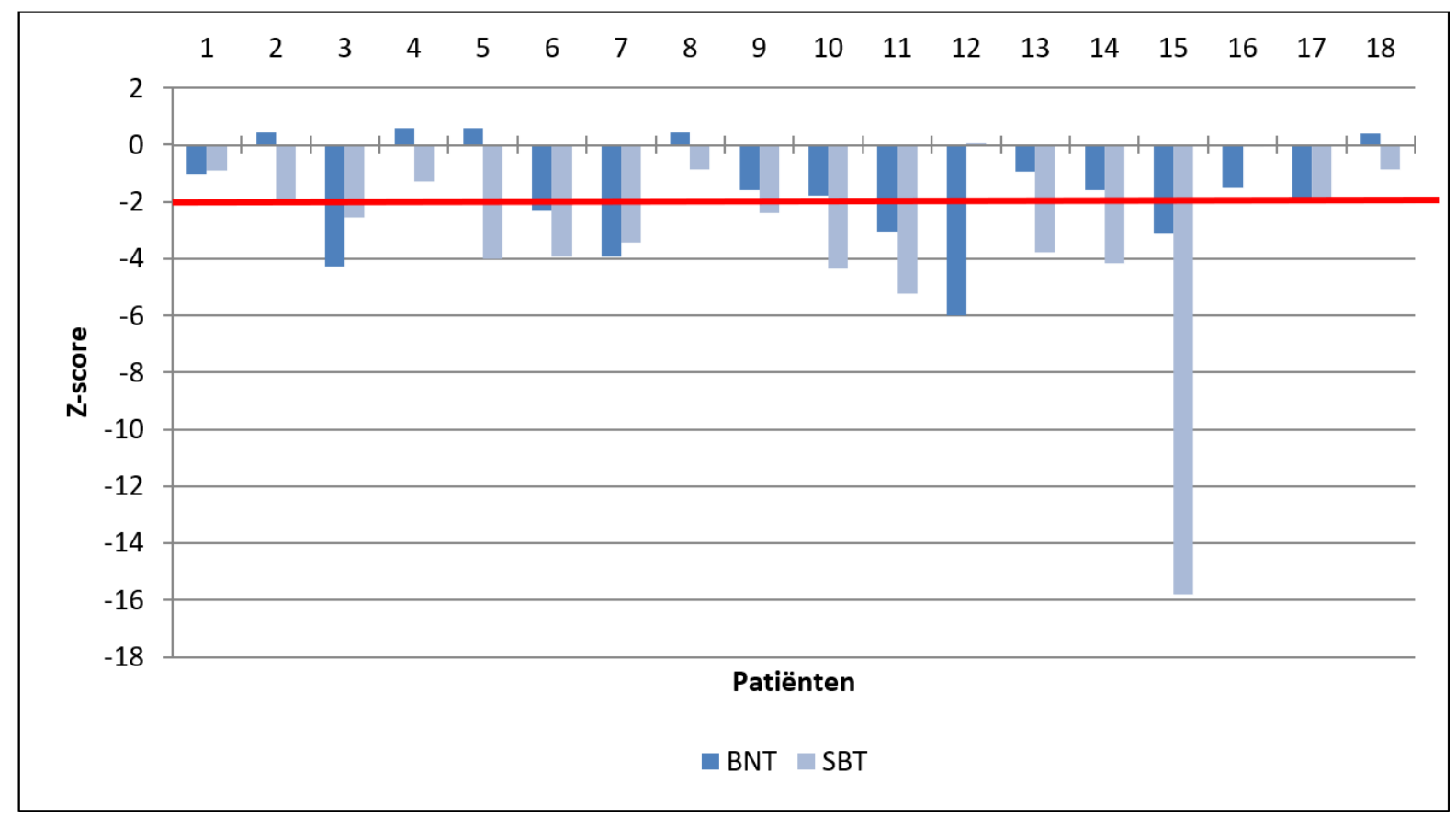

Figuur 2: Z-scores voor de BNT en de SBT (afwijkend bij een z-score groter dan -2, zie ook dikgedrukte lijn)

\section{Kwalitatieve vergelijking van goedscores en reactietijden}

Figuur 3 toont de z-scores voor correctheid op de BNT en SBT voor alle patiënten, tezamen 
met z-scores voor de gemiddelde reactietijden per patiënt waarmee de juist benoemde afbeeldingen benoemd werden. Patiënten maakten niet meer fouten op de SBT dan gezonde participanten (LGG: $M=1.06, S D=1.47$, gezond: $M=0.72, S D=1.04)$ ) $[t(36)=0.19, p=$ .10]. Hierbij zijn de data van twee gezonde participanten niet meegenomen in de analyse in verband met ontbrekende goedscores. Twee patiënten scoren afwijkend op de SBT $(12,15)$. Eén van deze patiënten is tevens de enige patiënt die een afwijkende score behaalde op de BNT (12). De andere patiënt (15) behaalde van de in totaal tien patiënten die een afwijkende score behalen op gemiddelde reactietijd, de meest afwijkende score.

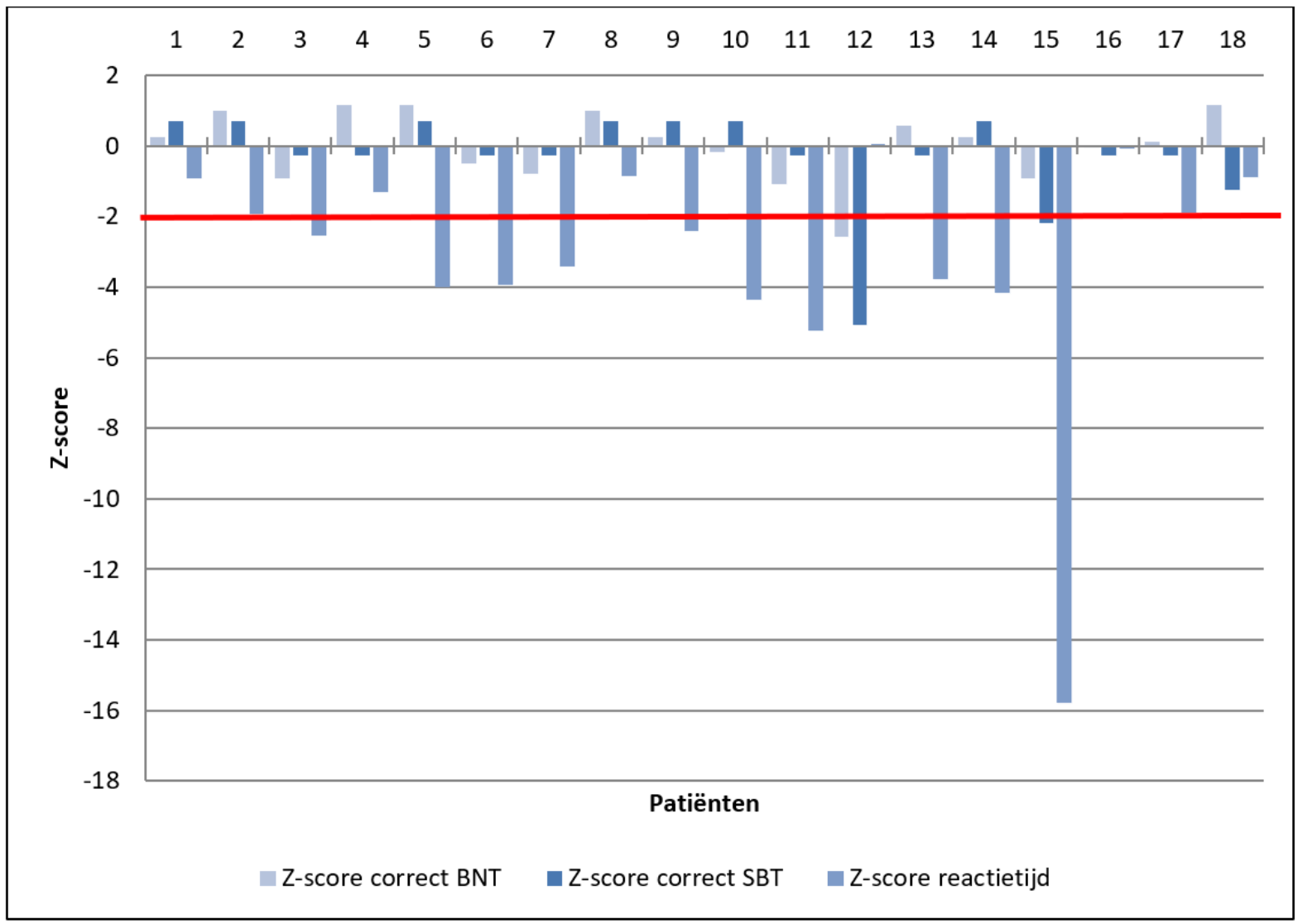

Figuur 3: Z-scores voor reactietijden en goedscores voor de BNT en de SBT (afwijkend bij een z-score groter dan -2, zie ook dikgedrukte lijn).

\section{Onderzoek naar de proportie verklaarde variantie door woordfrequentie en AoA}

Met behulp van een MRA ontstond in de groep gezonde participanten een significant model $(F(2,50)=3.568, p<.05)$, dat 9\% van de variantie verklaarde (Adjusted $\left.R^{2}=.090\right)$. Woordfrequentie of AoA alleen voorspelden de benoemsnelheden niet, hoewel beiden wel significant gecorreleerd waren met de gemiddelde benoemsnelheid. Ook waren woordfrequentie en AoA significant met elkaar gecorreleerd, maar dit was met een tolerantie van 0.918 geen probleem voor de validiteit. 
In de patiëntengroep ontstond een niet-significant model $(F(2,50)=2.786, p>.05)$, dat $6.4 \%$ van de variantie verklaarde (Adjusted $R^{2}=.064$ ). Woordfrequentie en AoA alleen voorspelden de benoemsnelheden ook hier niet significant. Alleen AoA correleerde significant met de gemiddelde benoemsnelheid. Woordfrequentie en AoA waren ook in deze groep significant met elkaar gecorreleerd, met een tolerantie van 0.918 was dit geen probleem voor de validiteit van de MRA.

\section{Discussie en conclusie}

Dit onderzoek laat zien dat patiënten met een LGG significant langzamer zijn in het benoemen van afbeeldingen dan gezonde participanten. Opvallend hierbij zijn de algehele korte reactietijden in beide groepen, die onder de verwachte grens van 1000 milliseconden liggen, in vergelijking met eerder onderzoek (Vandenberghe e.a., 2005; Wingfield e.a., 2006; Moritz-Gasser e.a., 2012). Dit kan wellicht verklaard worden door de alternatieve meetmethoden die in eerdere studies gebruikt zijn (bijv. gebruik van Powerpoint in combinatie met spraakopnames).

Het verschil in benoemsnelheden tussen de patiënten en de gezonde participanten kon niet verklaard worden door een lagere informatieverwerkingssnelheid, gemeten met TMTA. BNT-scores waren eveneens niet voorspellend voor de benoemsnelheden van de patiënten. Dit zou enerzijds kunnen betekenen dat de SBT een andere vaardigheid meet dan de BNT, of anderzijds dat de SBT sensitiever is voor het meten van woordvindproblemen. Om hier onderscheid tussen te maken is een kwalitatieve vergelijking gemaakt tussen het aantal afwijkende scores op de BNT en de SBT. De SBT diagnosticeerde alle patiënten met een afwijkende score op de BNT eveneens met woordvindproblemen, met uitzondering van één patiënt (deze patiënt maakte tevens de meeste fouten op zowel de BNT en de SBT, en de diagnose met een vermeend LGG later bijgesteld naar een hooggradig glioom). Omgekeerd werden vijf andere patiënten door de SBT geclassificeerd met woordvindproblemen, terwijl zij geen afwijkende scores op de BNT behaalden.

Opvallend is dat, van de hele patiëntengroep, de drie patiënten die pre-operatief zijn getest geen van allen uitval lieten zien op de SBT en twee van hen tevens niet op de BNT (patiënt $1 \& 4$ ). Deze twee patiënten behaalden echter ook geen optimale score op de SBT. Onderzoek van Ilmberger e.a. (2008), waarin patiënten een normale maar niet optimale score behaalden op een benoemtest, liet zien dat dit een krachtige voorspeller is voor postoperatieve afatische stoornissen.

Slechts twee patiënten behaalden afwijkende z-scores op de SBT. Dit betrof de eerder besproken patiënt die later gediagnosticeerd is met een hooggradig glioom. Een hogere tumorgraad kan samenhangen met ernstiger stoornissen (Habets e.a., 2014; Miotto e.a., 2011). Tevens betrof dit de enige patiënt met een recidief in de geteste groep waarbij veel data ontbrak wegens foutieve registraties van reactietijden door stotteren en aarzelingen van de patiënt tijdens het benoemen. Wellicht zijn deze twee patiënten om voorgenoemde redenen ernstiger aangedaan dan de andere patiënten waardoor zij afwijkende scores laten op de BNT. Afname van de BNT, waarop deze twee patiënten beiden uitvielen is wellicht voldoende 
sensitief voor het diagnosticeren van de woordvindproblemen bij dit type patiënten.

Naast deze bevindingen, zijn de verkregen data gebruikt om een vergelijking te maken met eerder gevonden effecten van woordfrequentie en AoA op benoemsnelheden. Woordfrequentie en AoA waren voor glioompatiënten niet maar voor gezonde proefpersonen wel voorspellend voor benoemsnelheden. Deze bevinding kan een rol spelen bij de langere benoemtijden die in het algemeen zijn gevonden bij glioompatiënten.

De huidige studie heeft een aantal tekortkomingen, waarvan groepsgrootte de meest in het oog springende is, maar dit past bij het zeldzame voorkomen van dit type hersentumor. Het gebruik van een MRA vereist een groot aantal participanten. Hoewel in de huidige studie het aantal voorspellende variabelen beperkt gehouden is, is het aantal participanten nog steeds minder dan optimaal. Hoewel de twee groepen echter redelijk heterogeen waren met betrekking tot leeftijd, geslacht en opleidingsniveau, was de patiëntengroep juist homogeen met betrekking tot het type patiënten dat is getest; alle patiënten zijn gediagnosticeerd met een vermeend LGG. Ondanks het feit dat alle betrokken patiënten gediagnosticeerd werden met een vermeend LGG, was er veel variatie met betrekking tot lokalisatie van de tumoren; zowel in de linker als in de rechter hemisfeer en zowel meer frontaal als meer temporaal gelegen en het moment van testen (pre- of post-operatief), waarbij er geen onderscheid gemaakt is tussen taalstoornissen als gevolg van het LGG of als gevolg van de operatie. Bij deze kleine groep kan de invloed van de lokalisatie van de tumor niet onderzocht worden en kunnen de resultaten ook niet gegeneraliseerd worden naar alle LGG-patiënten.

De sensitiviteit van de SBT binnen een heterogene groep met betrekking tot tumorlokalisatie kan echter duiden op de betrokkenheid van een groter subcorticaal netwerk dan bijvoorbeeld enkel het klassieke Broca-gebied, bij het benoemen van objecten. Daarnaast zou neurale reorganisatie dankzij de plasticiteit van de hersenen hierbij ook van invloed kunnen zijn (Duffau, 2014; Papagno e.a. 2012). In dat geval zou afname van de SBT ongeacht lokalisatie van het LGG te allen tijden relevant zijn voor het diagnosticeren van milde woordvindproblemen.

Een voordeel van de gebruikte meetmethode (E-Prime 2.0 in combinatie met een voicekey) is dat de reactietijden automatisch en nauwkeurig geregistreerd zijn door de voice-key, zonder dat stemopnamen geanalyseerd hoefden te worden. Dit bleek echter eveneens een nadeel te zijn aangezien door het gebruik van de voice-key veel data niet geanalyseerd konden worden doordat patiënten aarzelden bij het benoemen, wat exact de woordvindproblemen reflecteert die we trachtten te meten. Aangezien deze aarzelingen bij de analyses zijn weggelaten, is het mogelijk dat de woordvindproblemen ernstiger waren dan dit onderzoek weergeeft. Wanneer de overige benoemsnelheden bij de aarzelingen ook gemeten hadden kunnen worden, zouden waarschijnlijk grotere verschillen gevonden zijn tussen de groep patiënten en gezonde participanten.

In de huidige studie is geen rekening gehouden met de door patiënten gebruikte medicatie die de snelheid van informatieverwerking beïnvloed kan hebben. Aangezien met de scores op de TMT-A als maat voor de verwerkingssnelheid de langzamere benoemsnelheden niet konden worden verklaard, heeft dit de resultaten van de SBT waarschijnlijk niet beïnvloed. Wel werden glioompatiënten, in tegenstelling tot de gezonde participanten, getest in het kader van neuropsychologisch onderzoek, wat ervoor gezorgd kan hebben dat 
zij vermoeid of minder gemotiveerd waren. Emotionele stress, depressie en angst hebben mogelijk een effect gehad op de benoemsnelheden en andere testresultaten.

Toekomstig onderzoek zou meer deelnemers moeten includeren en met meer factoren rekening moeten houden. Er zou in later onderzoek een manier gevonden moeten worden om de benoemsnelheden ook na aarzelingen te meten, om een adequate indicatie te verkrijgen van de woordvindproblemen. Dit is wellicht mogelijk door E-Prime en de voice-key te gebruiken in combinatie met stemopnames. Ook zou de SBT bij verschillende klinische groepen onderzocht moeten worden, zoals afasiepatiënten met een CVA of een traumatisch hersenletsel, om de test bruikbaar te maken voor alle patiënten die milde woordvindproblemen ervaren. In een pilot-onderzoek met een eerste versie van de SBT bleken patiënten met een restafasie na een CVA trager te reageren dan een gezonde controlegroep (De Wilde \& Zijlstra, 2006).

Voor het diagnosticeren van gerapporteerde milde woordvindproblemen is het van groot belang de huidige bevindingen te repliceren zodat een sensitieve SBT ontwikkeld kan worden voor gebruik in de klinische praktijk.

\section{Referenties}

Alario, F. X., Ferrand, L., Laganaro, M., New, B., Frauenfelder, U. H., \& Segui, J. (2004). Predictors of picture naming speed. Behavior Research Methods, Instruments \& Computers, 36(1), 140-155. https://doi.org/10.3758/BF03195559

Bates, E., D’Amico, S., Jacobsen, T., Székely, A., Andonova, E., Devescovi, A., Herron, D., Lu, C.C., Pechmann, T., Pléh, C., Wicha, N., Federmeier, K., Gerdjikova, I., Gutierrez, G., Hung, D., Hsu, J., Iyer, G., Kohnert, K., Mehotcheva, T., Orozco-Figueroa, A., Tzeng, A, \& Tzeng, O. (2003). Timed picture naming in seven languages. Psychonomic Bulletin Review, 10(2), 344-380. http://dx.doi.org/10.3758/BF03196494

De Wilde H \& Zijlstra A. (2006) Snelle Benoemtest; ontwikkeld voor afasiepatiënten met lichte woordvindingsmoeilijkheden. Masterscriptie Taal- en Spraakpathologie. Faculteit Letteren. Radboud Universiteit Nijmegen

Duffau, H. (2014). The huge plastic potential of adult brain and the role of connectomics: new insights provided by serial mappings in glioma surgery. Cortex, 58, 325-337. https://doi.org/10.1016/j.cortex.2013.08.005

Duffau, H., Peggy Gatignol, S. T., Mandonnet, E., Capelle, L., \& Taillandier, L. (2008). Intraoperative subcortical stimulation mapping of language pathways in a consecutive series of 115 patients with Grade II glioma in the left dominant hemisphere. Journal of Neurosurgery, 109(3), 461-471. https://doi.org/ 10.3171/JNS/2008/109/9/0461

Ghyselinck, M., Custers, R., \& Brysbaert, M. (2003). Age-of-acquisition ratings for 2332 Dutch words from 49 different semantic categories. Psychologica Belgica, 43(3), 181214. Verkregen van http://hdl.handle.net/1854/LU-211746

Goodglass, H., \& Kaplan, E. (1983). The Assessment of Aphasia and Related Disorders. Philadelphia: Lea \& Febiger.

Habets, E. J., Kloet, A., Walchenbach, R., Vecht, C. J., Klein, M., \& Taphoorn, M. J. (2014). 
Tumour and surgery effects on cognitive functioning in high-grade glioma patients. Acta Neurochirurgica (Wien), 156(8), 1451-1459. https://doi.org/10.1007/s00701-0142115-8

Hunting-Pompon, R., Kendall, D., \& Bacon Moore, A. (2011). Examining attention and cognitive processing in participants with self-reported mild anomia. Aphasiology, 25(6-7), 800-812.

Ilmberger, J., Ruge, M., Kreth, F. W., Briegel, J., Reulen, H. J., \& Tonn, J. C. (2008). Intraoperative mapping of language functions: a longitudinal neurolinguistic analysis. Journal of Neurosurgery, 109(4), 583-592.https://doi.org/10.3171/JNS/2008/109/10/0583

Kaplan, E., Goodglass, H., Weintraub, S., \& Goodglass, H. (1983). Boston Naming Test. Philadelphia: Lea \& Febiger.

Kerkman, H., Piepenbrock, R., Baayen, R., Rijn, H., van. (1995). The CELEX lexical database. Philadelphia: Linguistic Data Consortium.

Mandonnet, E., Nouet, A., Gatignol, P., Capelle, L., \& Duffau, H. (2007). Does the left inferior longitudinal fasciculus play a role in language? A brain stimulation study. Brain, 130(Pt 3), 623-629. https://doi.org/10.1093/brain/awl361

McKenna, P., \& Warrington, E. K. (1983). Graded Naming Test. Windsor: NFER-Nelson.

Miotto, E. C., Junior, A. S., Silva, C. C., Cabrera, H. N., Machado, M. A., Benute,G. R. G., Lucia, M. C. S., Scaff, M., \& Teixeira, M. J. (2011). Cognitive impairments in patients with low grade gliomas and high grade gliomas. Arquivos de Neuropsiquiatria, 69(4), 596-601. https://doi.org/10.1590/S0004-282X2011000500005

Moritz-Gasser, S., Herbet, G., Maldonado, I. L., \& Duffau, H. (2012). Lexical access speed is significantly correlated with the return to professional activities after awake surgery for low-grade gliomas. Journal of Neurooncology, 107(3), 633-641.

https://doi.org/10.1007/s11060-011-0789-9

Papagno, C., Casarotti, A., Comi, A., Gallucci, M., Riva, M., \& Bello, L. (2012). Measuring clinical outcomes in neuro-oncology. A battery to evaluate low-grade gliomas (LGG). Journal of Neurooncology, 108(2), 269-275. https://doi.org/10.1007/s11060-012-08245

Randolph, C., Lansing, A. E., Ivnik, R. J., Cullum, C. M., \& Hermann, B. P. (1999). Determinants of confrontation naming performance. Archives of Clinical Neuropsychology, 14(6), 489-496. https://doi.org/10.1016/S0887-6177(98)00023-7

Roomer, E.K., Brok, S., Hoogerwerf, A.C., \& Linn, D.E. (2011). Boston BenoemTaak 2011. Een test voor woordvinding. Afdeling Logopedie, Hogeschool Utrecht, Nederland.

Satoer, D., Vork, J., Visch-Brink, E., Smits, M., Dirven, C., \& Vincent, A. (2012). Cognitive functioning early after surgery of gliomas in eloquent areas. Journal of Neurosurgery, 117(5), 831-838. https://doi.org/10.3171/2012.7.JNS12263

Satoer, D., Vincent, A., Smits, M., Dirven, C., \& Visch-Brink, E. (2013). Spontaneous speech of patients with gliomas in eloquent areas before and early after surgery. Acta Neurochirurgica (Wien), 155(4), 685-692. https://doi.org/10.1007/s00701-013-1638-8

Satoer, D., Visch-Brink, E., Dirven, C., \& Vincent, A. (2016). Glioma surgery in eloquent areas: can we preserve cognition? Acta Neurochirurgica (Wien), 158(1), 35-50. https://doi.org/10.1007/s00701-015-2601-7 
Satoer, D., De Witte, E., Smits, M., Bastiaanse, R., Vincent, A., Marien, P., \& Visch-Brink, E. (2017). Differential Effects of Awake Glioma Surgery in "Critical" Language Areas on Cognition: 4 Case Studies. Case Reports of Neurological Medicine, vol. 2017, artikel ID 6038641, 10 pagina's. https://doi.org/10.1155/2017/6038641

Severens, E., Van Lommel, S., Ratinckx, E., \& Hartsuiker, R. J. (2005). Timed picture naming norms for 590 pictures in Dutch. Acta Psychologica (Amst), 119(2), 159-187. https://doi.org/10.1016/j.actpsy.2005.01.002

Stoop K. (2009) Een analyse van de benoemvaardigheden van hersentumorpatiënten. Masterscriptie Taal- en Spraakpathologie. Faculteit Letteren. Radboud Universiteit Nijmegen.

Snodgrass, J. G., \& Vanderwart, M. (1980). A standardized set of 260 pictures: norms for name agreement, image agreement, familiarity, and visual complexity. Journal of Experimental Psychology: Human Learning and Memory, 6(2), 174-215. http://dx.doi.org/10.1037/0278-7393.6.2.174

Szekely, A., D’Amico, S., Devescovi, A., Federmeier, K., Herron, D., Iyer, G., Jacobsen, T., \& Bates, E. (2003). Timed picture naming: extended norms and validation against previous studies. Behavior Research Methods, Instruments \& Computers, 35(4), 621-633. https://doi.org/10.3758/BF03195542

Taphoorn, M. J., \& Klein, M. (2004). Cognitive deficits in adult patients with brain tumours. Lancet Neurology, 3(3), 159-168. https://doi.org/10.1016/S1474-4422(04)00680-5

Vandenberghe, R. R., Vandenbulcke, M., Weintraub, S., Johnson, N., Porke, K., Thompson, C. K., \& Mesulam, M. M. (2005). Paradoxical features of word finding difficulty in primary progressive aphasia. Annals of Neurology, 57(2), 204-209. https://doi.org/10.1002/ana.20362

Verhage, F. (1964). Intelligentie en leeftijd: onderzoek bij Nederlanders van twaalf tot zevenenzeventig jaar. Assen: Van Gorcum.

Wingfield, A., Brownell, H., \& Hoyte, K. J. (2006). Variable solutions to the same problem: aberrant practice effects in object naming by three aphasic patients. Brain \& Language, 97(3), 351-356. https://doi.org/10.1016/j.bandl.2005.11.005 